\title{
The role of coronary calcium score in predicting myocardial infarction Morning well, afternoon hell
}

\author{
Eliška Sovová', Milan Kamínek², Marek Richter', Milan Sova³, Miloš Táborský \\ $11^{\text {st }}$ Department of Internal Medicine, University Hospital Olomouc, \\ 2 Department of Nuclear Medicine, University Hospital Olomouc, \\ ${ }^{3}$ Faculty of Medicine, Palacký University in Olomouc, Czech Republic
}

Address: Assoc. Prof. Eliška Sovová, M.D., Ph.D., $1^{\text {st }}$ Department of Internal Medicine, University Hospital Olomouc, I. P. Pavlova 6, 77520 Olomouc, Czech Republic, e-mail: eliska.sovova@seznam.cz

Coronary artery calcium (CAC) score could be very useful in predicting myocardial infarction or cardiac death, in particular amongst those who are at intermediate risk of coronary events or in diabetic patients. Coronary artery
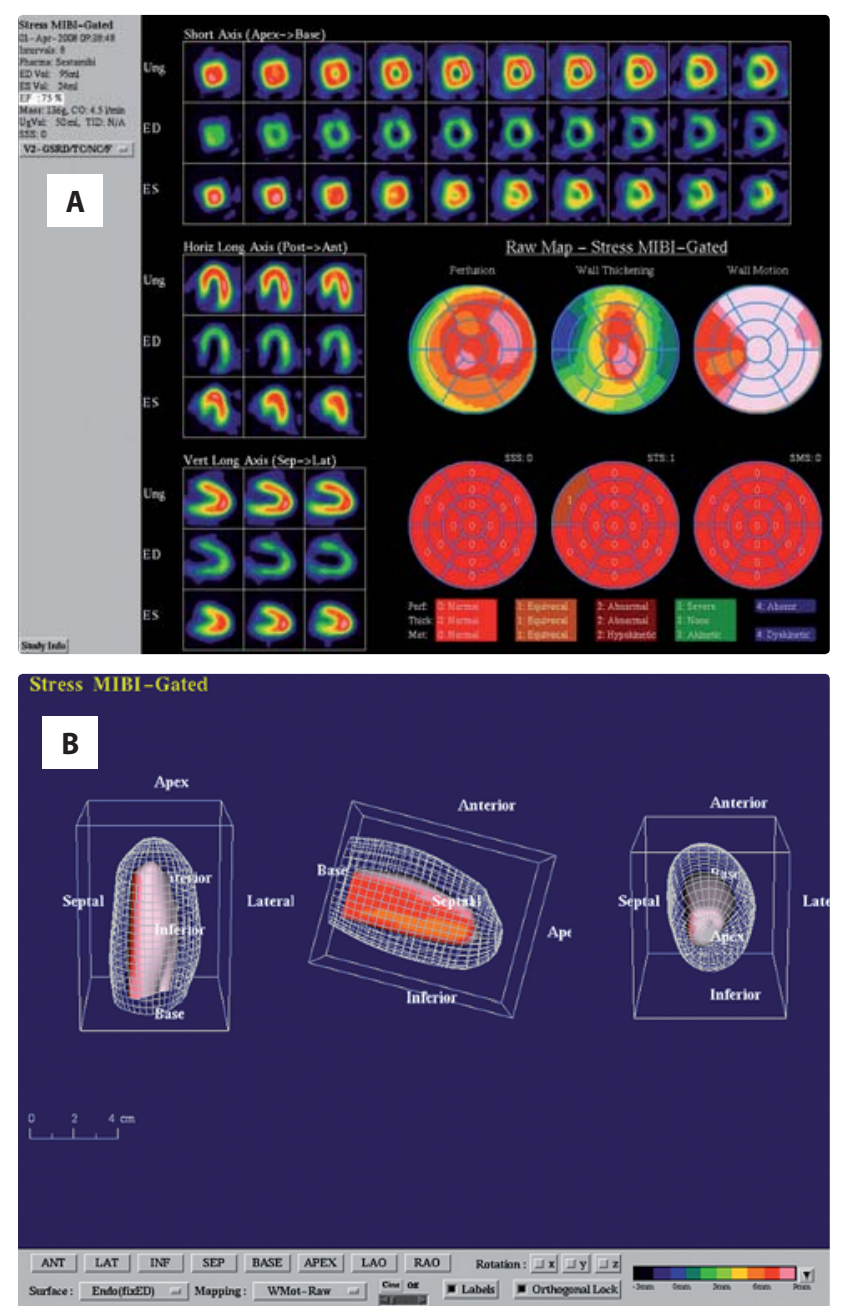

calcium has been shown to be a better predictor of cardiovascular events than carotid intima-media thickness. Combining SPECT with CAC improves sensitivity and specificity for the detection of significant coronary artery

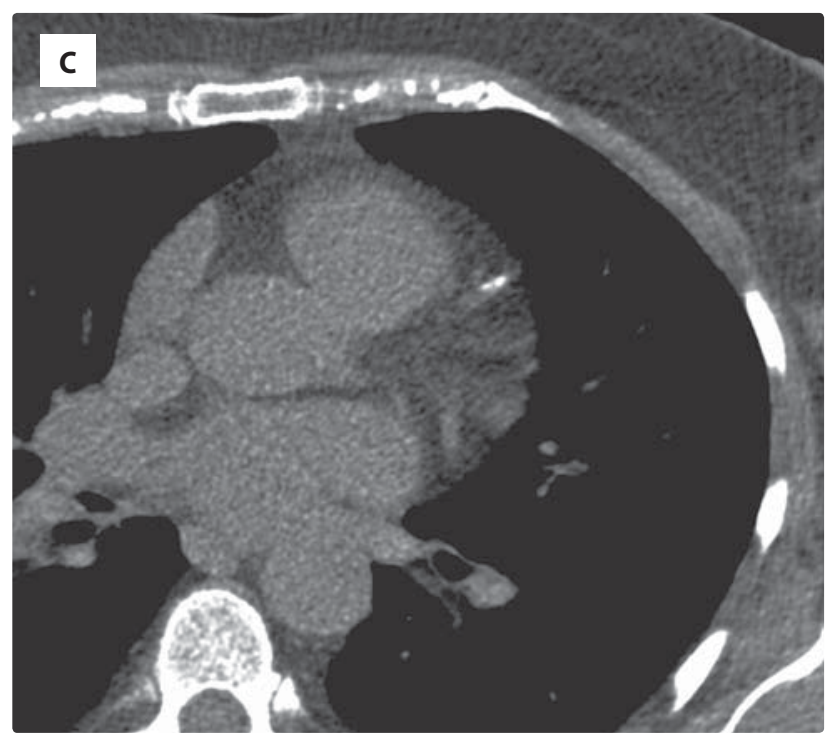

Figure 1 A 53-year-old woman without symptoms made an appointment for a preventive examination due to her positive family history (her father had a myocardial infarction at the age of 55) in the year 2008. She had a history of arterial hypertension, received beta-blockers and was a smoker. Physical examination: BP 180/100, heart rate 78 , without any pathology. Laboratory: serum cholesterol level $6.08 \mathrm{mmol} / \mathrm{l}, \mathrm{ApoB} 0.89$ $\mathrm{mmol} / \mathrm{l}, \mathrm{HDL}$-cholesterol $1.78 \mathrm{mmol} / \mathrm{l}$, LDL-cholesterol $4.0 \mathrm{mmol} / \mathrm{l}$, Lp(a) $0.024 \mathrm{mmol} / \mathrm{l}$, glucose $5.6 \mathrm{mmol} / \mathrm{l}$, fibrinogen $4.58 \mathrm{mmol} / \mathrm{l}$. Within our study "CVD and relatives", ${ }^{1-8}$ she had an echo exam with normal systolic left ventricular function and SPECT with normal heart perfusion (Figures 1A, 1B). ${ }^{4,5}$ The coronary artery calcium score (Figure $1 C$ ) showed only small calcification on the left descending artery (LAD) (Agatson score 15). ACE inhibitors and a statin were recommended. 


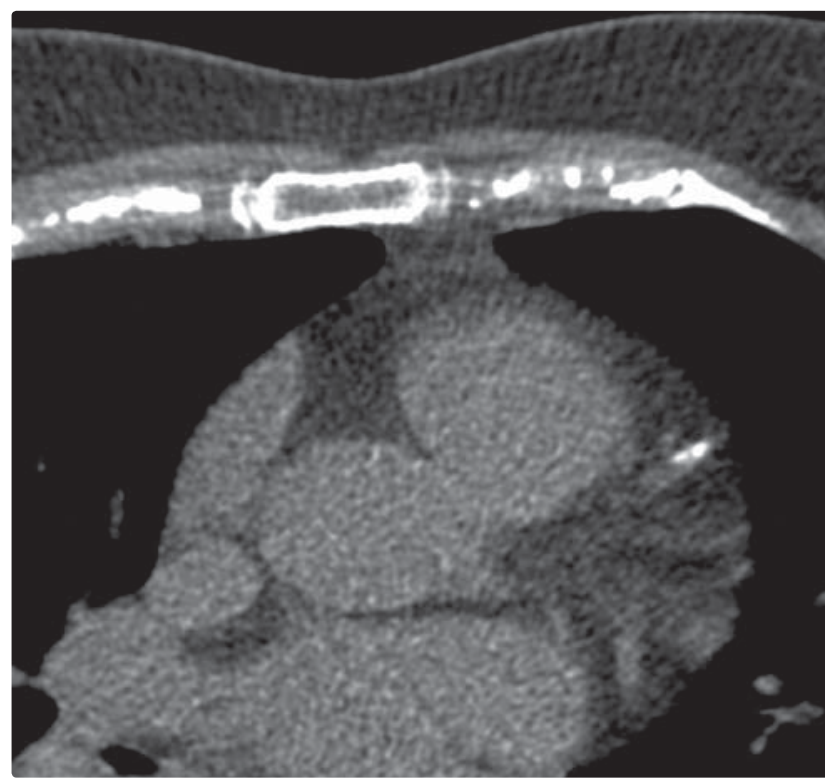

Figure 2 The patient reported for her yearly follow-up examination in the morning of 6 April 2009. She did not complain of any cardiac symptoms. Her medication consisted of a beta-blocker, statin, ACE inhibitor, and moxonidine. The patient had not stopped smoking. Physical examination: BP 130/80, heart rate 65 , without any pathology. Laboratory: serum cholesterol $4.94 \mathrm{mmol} / \mathrm{l}$, ApoB $0.83 \mathrm{mmol} / \mathrm{l}, \mathrm{HDL}$-cholesterol 1.53 $\mathrm{mmol} / \mathrm{l}$, LDL-cholesterol $3.01 \mathrm{mmol} / \mathrm{l}, \mathrm{Lp}$ (a) $0.357 \mathrm{mmol} / \mathrm{l}$, glucose $5.1 \mathrm{mmol} / \mathrm{l}$, fibrinogen $4.7 \mathrm{mmol} / \mathrm{l}$. Her risk score (SCORE) was $2-3 \%$. The CAC score showed a small calcification on the LAD (Agatson score 32).

disease (CAD). The National Education Program Adult Treatment Panel III guidelines recommend CAC score as on option for advanced risk assessment in appropriately selected individuals.

The absence of a positive CAC score or a mild CAC score does not exclude the occurrence of myocardial infarction.

We present the case of a 53-year-old woman with an intermediate coronary risk score (smoking, hypertension, lipid disorders, positive family history), on medication (beta-blockers, ACE inhibitors, statins), who had only a mildly positive CAC score (Agatson 32), with a small calcification on the left coronary artery in an exam in the morning and had an acute myocardial infarction on the right coronary artery in the afternoon.

\section{References}

1. Schepis T, Gaemperli O, Koepfli P, et al. Added value of coronary artery calcium score as an adjunct to gated SPECT for the evaluation of coronary artery disease in an intermediate-risk population. J Nucl Med 2007;48:1424-1430.

2. Folsom AR, Kronmal RA, Detrano RC, et al. Coronary artery calcification compared with carotid intima-media thickness in the prediction of cardiovascular disease incidence: The Multi-Ethnic Study of Atherosclerosis. Arch Intern Med 2008;168:1333-1339.

3. Godsland IF; on behalf of the PREDICT study investigators. Prospective evaluation of coronary artery calcium in predicting cardiovascular events in asymptomatic patients with type 2 diabetes. $77^{\text {th }}$ European Atherosclerosis Congress April 27, 2008, Istanbul, Turkey.

4. Schuijf JD, Wijns W, Jukema W, et al. A comparative regional analysis of coronary atherosclerosis and calcium score on multislice $C T$ versus myocardial perfusion on SPECT. J Nucl Mec 2006;47:1749-1755.
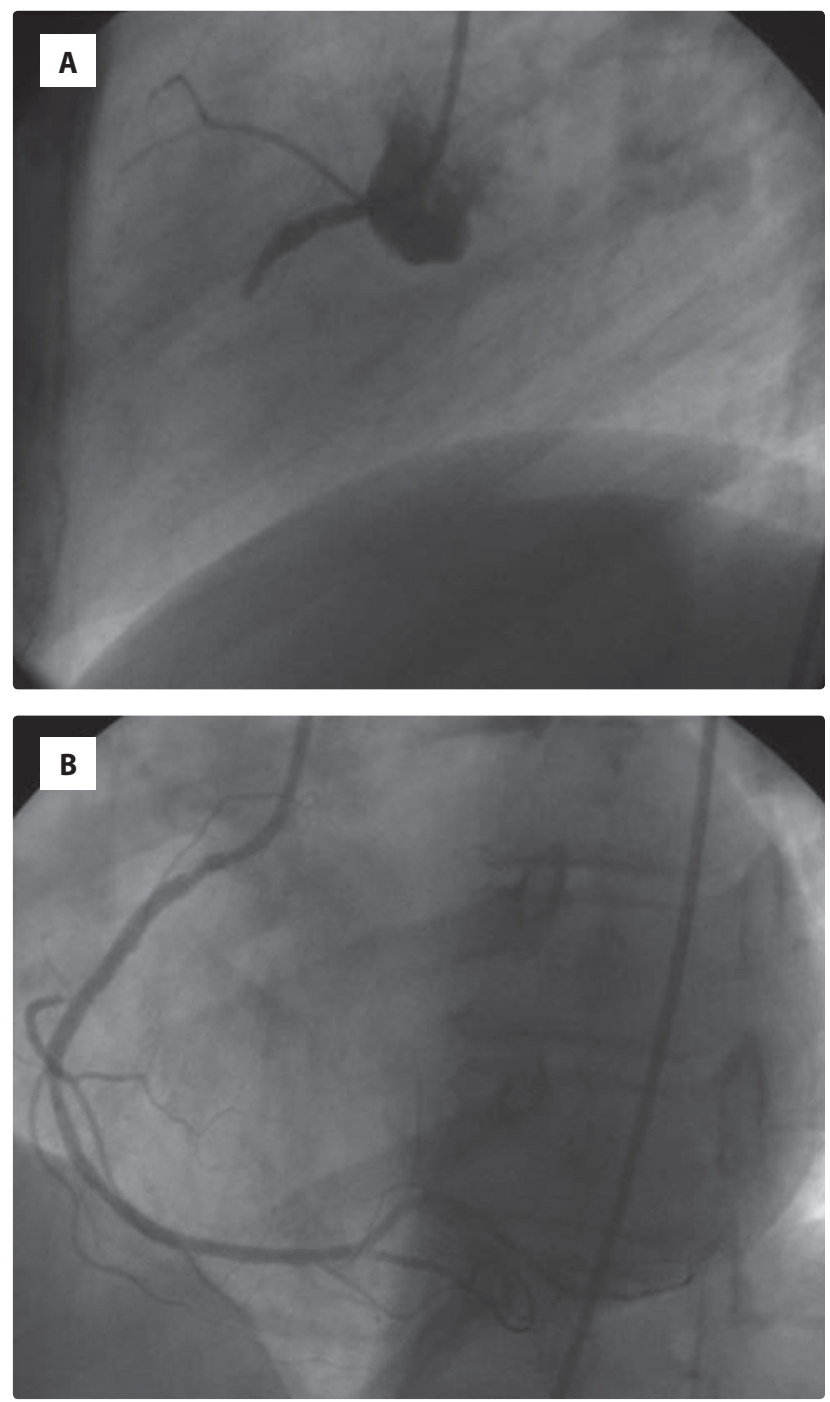

Figure 3 In the same afternoon, she experienced chest pain and visited a doctor in another hospital. There were signs of acute myocardial infarction of the inferior wall on the ECG and the patient was sent to the University Hospital in Olomouc for acute $\mathrm{PCl}$. Defibrillation was necessary in light of ventricular fibrillation at the time of the myocardial infarction. Figure $3 \mathrm{~A}$ depicts the zero blood flow in the right coronary artery and Figure $3 \mathrm{~B}$ the result of the $\mathrm{PCl}$-induced $\mathrm{TIMI} 3$ flow in the right coronary artery. This case report confirms the theory that the CAC score may miss soft plaques playing an important role in acute coronary syndrome. The MESA study revealed that $4 \%$ of patients with a zero CAC score may have significant coronary obstruction. ${ }^{9}$

5. Uebleis C, Becker A, Griesshammer I, et al. Stable coronary artery disease: prognostic value of myocardial perfusion SPECT in relation to coronary calcium scoring - long-term follow up. Radiology 2009;253:682-690.

6. Third Report of the National Cholesterol Education Program (NCEP) Expert Panel on Detection, Evaluation and Treatment of High Cholesterol in Adults (Adult Treatment Panel III). Circulation 2002;106:3143-3421.

7. Rumberger JA. Role of noninvasive imaging using computed tomography for detection and quantification of coronary atherosclerosis. Future Cardiol 2008;4:269-283.

8. Kim JH, Machac J, Travis A, et al. Relationship between myocardial flow reserve and coronary calcium score measured by $82 \mathrm{Rb} P E T / C T$ in intermediate-risk patients. Clin Nucl Med 2006;31:117.

9. Rosen BD, Fernandes V, McClelland RL, et al. Relationship between baseline coronary calcium score and demonstration of coronary artery stenoses during follow-up. MESA Multi-Ethic Study of Atherosclerosis. J Am Coll Cardiol Cardiovasc Imaging 2009;2:1175-1183. 